\title{
Semantic facilitation across sensory modalities in the processing of individual words and sentences
}

\author{
DAVID A. SWINNEY, WILLIAM ONIFER, PENNY PRATHER, \\ and MAX HIRSHKOWITZ \\ Tufts University, Medford, Massachusetts 02155
}

\begin{abstract}
The effect of semantic priming upon lexical decisions made for words in isolation (Experiment 1) and during sentence comprehension (Experiment 2) was investigated using a crossmodal lexical decision task. In Experiment 1, subjects made lexical decisions to both auditory and visual stimuli. Processing auditorily presented words facilitated subsequent lexical decisions on semantically related visual words. In Experiment 2, subjects comprehended auditorily presented sentences while simultaneously making lexical decisions for visually presented stimuli. Lexical decisions were facilitated when a visual word appeared immediately following a related word in the sentential material. Lexical decisions were also facilitated when the visual word appeared three syllables following closure of the clause containing the related material. Arguments are made for autonomy of semantic priming during sentence comprehension.
\end{abstract}

Questions concerning the nature of semantic priming have come to hold an increasingly important position in current modeling of human recognition. Not only do a number of recent cognitive theories utilize evidence based on variations of this effect as the foundation for their positions (e.g., Collins \& Loftus, 1975; Posner \& Snyder, 1975), but investigations of several very specific characteristics of cognitive processing (e.g., automaticity) have been centered around their involvement in semantic priming (Neely, 1977). The lexical decision task, in particular, has held a prominent place in these investigations of semantic priming, at least in part because the nature of lexical processing involvement in this task has been assumed to be well known and to have limited bounds.

In some of the more basic studies of semantic priming, Meyer and his associates (Meyer, Schvaneveldt, \& Ruddy, 1975; Meyer, Schvaneveldt, \& Ruddy, Note 1) have shown that, for both simultaneous and successive visual presentation of words, lexical decisions are facilitated if the words are semantically related. While there is often some aspect of this facilitation under control of specialized strategies, several experiments have demonstrated that there is also an automatic component to this effect, at least insofar as conventional concepts of automaticity are concerned (e.g., Fishler, 1977; Forback, Stanners, \& Hochhaus, 1974; Neely, 1977; Posner \& Snyder, 1975; Tweedy, Lapinski, \&

This research was supported, in part, by Grant 1RO3 UH29885-01 from NIMH. The authors express their appreciaion to Marie Banich, for her assistance in the collection of much If the data for this experiment, and to Donald J. Foss and Javid $T$. Hakes, for their valuable critjcisms of an earlier draft if this paper.
Schvaneveldt, 1977; Schulman \& Davidson, Note 2). Such automatic priming has been shown to obtain for both associated and nonassociated (but semantically related) words.

The nature of this automatic component of semantic priming is, however, still far from being well understood. For one thing, despite the fact that it is often cited as a major explanation for contextual effects in cognition (e.g., Collins \& Loftus, 1975), little is known about how semantic priming (automatic or otherwise) interacts with other, ongoing, cognitive processes to produce these context effects. Certainly, the question of whether such semantic priming is largely autonomous or whether it interacts in any discernible and interesting fashion with other aspects of ongoing semantic/syntactic processing has serious consequences for any model of language comprehension (see Marslen-Wilson \& Welsh, 1978; Swinney \& Hakes, 1976, for further discussion).

In addition, the basic domains over which semantic priming is effective are little understood at this time. There is an implicit assumption made in most of the visual priming work that priming is a "central" process, one equally available to sensory inputs from different sources and modalities. However, the assumption is not necessarily warranted by the data. While a literature has recently developed which examines a few aspects of semantic processing across sensory modalities, largely involving the integration of pictures with words and sentences (see, e.g., Carpenter \& Just, 1975; Gehring, Toglia, \& Kimble, 1976; Harris, Morris, \& Bassett, 1977; Pellegrino, Rosinski, Chiesi, \& Siegel, 1977), our knowledge of semantic priming is based almost entirely on within-mode (visual) examinations (see, however, Cohene, Smith, \& Klein, 1976, for an exception to this rule). It has not been adequately or extensively demon- 
strated that the characteristics of semantic priming displayed under these visual paradigm examinations are, in fact, general, universal features, applicable to different sensory modalities. While at first blush it might seem that such effects are likely to be identical across various modalities, there is some reason to question that view; work on a number of presumably "central" processes investigated with tasks in one sensory modality have failed to replicate in other modalities. For example, the homograph effect reported by Rubenstein, Lewis, and Rubenstein (1971) and others using a visual lexical decision task has not been found using an auditory lexical decision task (Holley-Wilcox, Note 3). While there are a multitude of potential explanations for failures to replicate across modality, all such explanations require reconsideration of not only the task used, but also the nature of the (supposedly "central") cognitive process under investigation. Certainly, one method of grasping the true nature of such processes is from the vantage offered by examining their effects in differing sensory modalities.

Thus, the present research is focused on two problems and is designed in two stages. The first involves extending the examination of semantic priming into areas involving intersensory integration, by investigating whether priming effects obtain across sensory modali. ties in a lexical decision task. We wished not only to discover whether these effects would exist and/or be equivalent to same-modality priming results, but also to determine whether such cross-modal priming could provide the basis for a new task to be used in the measurement of lexical and semantic processes that occur during sentence comprehension. To this end, a crossmodal lexical decision task was employed in a design intended to minimize other specialized control strategies and to allow evaluation of response biases in the priming effect. The second, related, problem is that of determining the nature of semantic priming associated with lexical processing that occurs during sentence comprehension, with particular focus upon the level of interaction (or autonomy) which exists in the process. As the efficacy of studying the second problem depends upon a successful demonstration of cross-modal priming (Experiment 1), further discussion of this problem follows Experiment 1.

\section{EXPERIMENT 1}

\section{Method}

Subjects. Twenty-four undergraduate students participated as partial fulfillment of an introductory psychology course requirement. The subjects were randomly assigned to one of two experimental groups.

Materials and Procedure. Twenty pairs of words were created by pairing a word with its first or second associate from the California Word Norms (Postman \& Keppel, 1970). Twenty control word pairs were also created by re-pairing the original items so that there was no obvious relationship between the members of the pairs. An additional 20 pairs of words, selected from the same source, were utilized to generate word-nonword pairs. For each of the second (associated) words of these pairs, a single pseudorandomly selected letter was replaced by another letter to produce an orthographically legal, pronounceable nonword (pseudoassociate). A final set of 20 word-nonword pairs was created by reordering the pseudoassociates to produce control pairs.

These materials were split into two equivalent material sets, designed so that a subject would never be presented with any word (or nonword) more than once. Each set contained 10 associated word pairs and 10 control word pairs (taken from the controls generated for the "other" 10 experimental word pairs). The same design procedure held for the word-nonword (pseudoassociate) pairs and their controls. In addition, both sets contained five nonword-word and five nonword-nonword pairs. Items within sets were randomly ordered.

This study was conducted under the on-line control of a DEC PDP-8 minicomputer. Materials were presented in a continuous, modality alternating fashion. The first item of each pair was presented auditorially over headphones and was followed immediately by the visually presented second item. Auditory items were recorded on tape, with a 5-sec interval between each item. Average duration of each auditory word was approximately $550 \mathrm{msec}$. The second, visual, item in each pair was displayed on a CRT screen immediately upon offset of the auditory item. Visual items were presented for a 1-sec duration: letters comprising each visual item were presented in a $3 / 16 \mathrm{x}$ $1 / 8 \mathrm{in}$. display, at a distance of $2 \mathrm{ft}$. Subjects were instructed to decide whether each auditorially presented item was a word or a nonword. If the auditory item was judged to be a word, the subject was then required to make a lexical decision on the following visually presented item by pressing, as rapidly as possible, one of two buttons (word/nonword). Subjects kep1 their hands on the two buttons and watched a fixation dot on the CRT screen throughout the experiment. When the auditory item was judged to be a nonword, no decision was required or the second, visually presented item. Eight practice trials pre ceded each experimental session. Responses and reaction time: were recorded for all visually presented materials.

\section{Results}

Mean reaction times to the visually presented word: were calculated for each subject and for each experi mental condition. The mean reaction time to the contro (unprimed) words was $.886 \mathrm{sec}$, while that for word: which followed the presentation of related auditory words was $.803 \mathrm{sec}$. These data were submitted to ar analysis of variance under a min $\mathrm{F}^{\prime}$ criterion (Clark 1973). The observed .083-sec facilitation effect due ts priming was significant $\left[\min \mathrm{F}^{\prime}(1,36)=4.46, \mathrm{p}<.05\right.$ ] A similar comparison was made for the reaction times ti the nonword (pseudoassociate) items and their "con trols." The mean reaction time to the control pseudo associate condition was $1.053 \mathrm{sec}$, and the mean reactio time to the "related" pseudoassociate condition wa $1.087 \mathrm{sec}$. These conditions did not differ significantl under an analysis of variance $\left[\min F^{\prime}(1,36)=.41\right]$

An analysis of the incorrect responses within th various conditions was also performed. The error rate fo the pseudoassociate (nonword, primed) conditio (11 errors) and its control (10 errors) did not diffe significantly $\left(\chi^{2}=.05\right)$. The error rates for the assc ciated word pairs (1 error) and their controls (15 error: did, however, differ $\left(\chi^{2}=135, p<.001\right)$. 


\section{Discussion}

The results demonstrate that semantic priming occurs across sensory modalities (or, at least, from the auditory to the visual modality) and suggest that such priming is, indeed, a "central" process. The magnitude of the facilitation and the error rate correspond quite reasonably to values reported for intramodality priming. It should be noted that this facilitation occurred even though less than $20 \%$ of the items presented were related in any obvious sense. The strength of the priming effect, even in the face of this relatively low ratio of related to unre. lated items, suggests that automatic priming is most likely taking place (e.g., Tweedy, Lapinski, \& Schvaneveldt, 1977). The fact that error rates were no higher for the nonword materials under the "pseudopriming" than under the "control" condition adds further, indirect, support for this hypothesis. If subjects utilized some special response strategy, such that any item following an auditory word was deemed likely to be an associate of that word (and, thus, wordness could be determined by accepting anything that, on superficial analysis, resembled an associate of the auditory word), then one would expect a higher false positive rate on the "primed" pseudoassociate nonwords than on their controls. As no such effect occurred, it appears reasonable to assume that the effect obtained cross-modally here corresponds to the automatic priming effect reported elsewhere.

While establishing the semantic priming effect in a cross-modal situation adds to our knowledge of the nature of priming itself, it also provides a mechanism through which we can study the nature of semantic priming during ongoing sentence comprehension. In fact, it holds the promise of being one of the few such tasks that can measure moment-to-moment semantic processing while providing only minimal interference with normal ongoing comprehension processes. In the typical experimental paradigm used to study aspects of online sentence comprehension, subjects are required to either analyze or perform specialized decisions upon certain material in a sentence while simultaneously comprehending that sentence. It is clear that the higher and lower order constraints normally operating during comprehension may undergo marked changes in these task situations (see Cutler \& Norris, in press, for a review of these tasks). There is a possible alternative: If subjects are asked to comprehend a normal sentence and simultaneously to perform another, apparently unrelated, task-one that does not require conscious analysis of parts of the sentence or any major increase in memory load-then only minimal (if any) disruption of automatic sentence comprehension processes (in the sense discussed by Shiffrin \& Schneider, 1977) should occur. Cross-modal priming appears to be just such a task.

Semantic priming itself has often been suggested to be the basis for context effects that occur during sentence comprehension (e.g., Collins \& Loftus, 1975), and research examining the involvement of semantic contexts in the resolution of lexical ambiguities has, indirectly, suggested that something akin to priming may be going on (Foss \& Jenkins, 1973; Swinney \& Hakes, 1976; Cutler \& Foss, Note 4). However, the actual nature of priming during sentence comprehension has just recently begun to be investigated (see Blank \& Foss, 1978; Morton \& Long, 1976). The basic question to be explored here is that of how semantic priming will be affected by the ongoing lexical, syntactic, and semantic decisions made during sentence comprehension. As a first blush approach to this question, two factors appear to be worthy of study. The first involves investigation of effects of processing decisions about sentence structure upon the priming effect, while the second involves analysis of the effects of distance and intervening lexical material upon priming. The question involved in the second of these is relatively self-evident, but the first may require some discussion.

The deep structure clause has been acknowledged to be a major processing unit in ongoing comprehension (see Fodor, Bever, \& Garrett, 1974, for a review of much of this material), and a number of sentence processing models revolve around the cohesiveness of this unit. One important theoretical argument that has evolved from the study of clausal units in general is the concept that, once a clause is completed, information derived from that clause is shifted from immediate (working) memory. Caplan (1972) and Jarvella (1971), among others, have provided what appears to be strong experimental evidence supporting this hypothesis. If semantic priming is a process which functions only on information that is under "current" consideration by the comprehension device (thereby aiding lexical access and decision making for items undergoing "current" structural and semantic analysis)-a suggestion that certainly fits the spirit of the interpretation generally given to the function of clausal units (Fodor et al, 1974)-it should be the case that lexical information shifted from the working memory will not provide priming for items occurring during a later clause. However, semantic priming should certainly hold for items presented during processing of the clause that contains the priming material (Swinney \& Hakes, 1976).

The second experiment, using the cross-modal priming paradigm in a sentence comprehension setting, investigated the nature of semantic priming both within and across clauses during sentence comprehension and the effects of interpolated material on this priming. Two different levels of associative semantic relationships (high and low) were utilized in this study, rather than the traditional "highly associated" vs. "nonassociated" materials. The rationale for this is that, whereas one cannot always be certain of the lack of relationship in supposed "nonassociated" materials, a very low (but known) relationship can provide a useful, known, measure of control. 


\section{EXPERIMENT 2}

\section{Method}

Subjects. Forty students from Tufts University participated in the study. Subjects were paid $\$ 2.50$ for their participation. Subjects were randomly assigned to one of the four experimental groups created by the tapes and visual word lists conditions.

Materials. A set of 12 pairs of experimental sentences was prepared in which sentences were matched as closely as possible with regard to frequency and length of words. The sentences of a pair were not, however, semantically related. The major difference between the members of a sentence pair was that one member contained a well-marked relative clause (both subject and object relative clauses were used), while the other did not. A single priming word existed in each sentence just prior to the clause boundary (or at a similar point in the matched, paired sentence). These sentences were pseudorandomly arranged on a tape recording, along with 36 control sentences.

Two words were prepared to go with each experimental sentence. The words were to be presented visually while the auditory sentence was being comprehended. One of the two visual words was a high associate of the auditory priming word (one of the first five associates on the Jenkins, 1970, norms) and the other was a low associate (below 25 on the word norms) of the designated priming word in the sentence. The two words were matched for frequency (Kučera \& Francis, 1967) and length (number of letters).

The words were arranged into two lists. Each list contained one-half of the high-associate and one-half of the low-associate words. These were equally distributed (six each) across sentences containing clause boundaries and those without clause boundaries. In addition, the visual word lists included 24 strings of letters that did not form words. These were arranged to appear with 24 of the control sentences. There were an additional 12 word-sentence pairs in which there was no relationship between the visual word and any word in the control sentence with which it appeared. This category was included to help minimize special strategies in the lexical decision process.

These materials were then completely duplicated. One set (one tape and the two lists) was arranged so that the associated visual words appeared immediately after the designated priming word occurred in an auditory sentence. This was accomplished by placing a $1,000-\mathrm{Hz}$ signal coincident with the offset of the priming word. The signal was inaudible to the subjects. Presentation of the word on a CRT screen was controlled by a PDP-8 computer triggered by the signal. The other (duplicate) set of materials differed only in that the visual words appeared after three syllables of intervening material $\left(2 \frac{1}{2}\right.$ words) had occurred following the auditory priming word. The materials were organized so that in sentences containing a clause boundary the related visual word always occurred (whether in the immediate or delayed condition) at some point following the end of the clause containing the priming word. All visual items were displayed for $750 \mathrm{msec}$.

Thus, the experimental design involved three within-subjects variables (clause boundary, associative strength, and items within condition) and two between-subjects variables-presentation point (immediate vs. delayed visual word presentation) and word lists, a materials counterbalancing variable.

Procedure. Each subject was seated in a booth, in which he/she listened to sentences over headphones and simultaneously watched a fixation point on a visual display screen in front of him/her. Subjects were told they had two tasks to perform. First, they were told to listen carefully to, and to try to comprehend, the sentences they heard because there was to be a test of comprehension at the end of the experiment. [This was a recognition test in which subjects were presented with 20 sentences and told to indicate which ones they had heard in the experimental materials. Distractor (new) sentences in this test were created by taking key content words from actual sentences in the experiment and placing them in sentences that differed in theme and content from the original sentences. Data were included in this study only for those subjects scoring $90 \%$ or better on this test.] Subjects were told that their second (and equally important) task was to watch the visual display screen and, whenever a letter string appeared, to decide as quickly as possible whether the letter string formed a word or a nonword and to press the appropriate button. Five practice trials were given.

\section{Results}

Mean reaction times were computed for each experimental condition for each subject. These data were subjected to an analysis of variance. The main effect for associative strength (high vs. low) was significant in both an analysis employing subjects as the random factor $[F(1,36)=31.9, p<.0001]$ and an analysis employing both subjects and materials as random factors $\left[\min \mathrm{F}^{\prime}(1,15)=4.89, \mathrm{p}<.05\right]$. The main effects for clause boundary $[F(1,36)=.20]$, immediate vs. delayed presentation point $[F(1,36)=.32]$, and all interactions with the materials counterbalancing variable all failed to reach significance. Finally, while the Clause Boundary by Presentation Point and the Clause Boundary by Associative Strength interactions were not significant $[F(1,36)=.13, F(1,36)=.52$, respectively $]$, the Presentation Point by Associative Strength interaction was significant under an analysis employing subjects as a random factor $[F(1,36)=4.64, p<.03]$ but not under $\min F^{\prime}[F(1,23)=1.46]$.

Mean reaction times for the comparisons of particular importance in this study (those involved in the Presentation Point by Associative Strength by Clause Boundary interaction) are displayed in Table 1. Planned analyses were performed on the critical comparisons comprising this interaction. In these, significant priming was found to occur (high associative strength items were responded to significantly faster than were low associated strength items) in the immediate presentation point condition, both when there was an intervening clause boundary $[\mathrm{t}(19)=-2.579, \mathrm{p}<.005]$ and when there was no clause boundary present $[\mathrm{t}(19)=-5.988$, $p<.0001$ ] . These same priming effects held, although not so robustly, for the delayed presentation point condition, both when there was a clause boundary present $[t(19)=-1.707, p<.053]$ and when there was no clause boundary present $[\mathrm{t}(19)=-1.998, \mathrm{p}<.01]$.

Table 1

Mean Reaction Times (in Milliseconds) for the Clause Boundary by Presentation Point by Associative Strength Interaction

\begin{tabular}{lccccc}
\hline & \multicolumn{3}{c}{$\begin{array}{c}\text { Sentential } \\
\text { No Clause } \\
\text { Boundary }\end{array}$} & & \multicolumn{2}{c}{$\begin{array}{c}\text { Structure } \\
\text { Clause } \\
\text { Boundary }\end{array}$} \\
\cline { 2 - 3 } \cline { 5 - 6 } Associative Strength: & High & Low & & High & Low \\
\hline $\begin{array}{l}\text { Presentation Point } \\
\text { Immediate }\end{array}$ & 692 & 754 & & 695 & 736 \\
Three-Syllable Delay & 728 & 751 & & 727 & 750 \\
\hline
\end{tabular}




\section{Discussion}

These results appear to support three relatively clearcut conclusions. First, semantic priming does occur during ongoing sentence comprehension. This basic effect is in agreement with the results reported by both Blank and Foss (1978) and Morton and Long (1976). In these studies, within-sentence facilitation effects, which were under the control of semantic relationships existing between key words in sentences, were demonstrated with a phoneme-monitoring task. The priming obtained here (and in these previous studies) has many of the characteristics found in the priming of isolated words, suggesting, at the least, that some of the word processing characteristics that have been determined from isolated-word priming studies may be applicable to models of normal comprehension. While the use of a very low, but known, level of associativity in the priming control condition provided a useful and satisfactory control measure for this study, the absolute level of facilitation is undoubtedly underestimated by this method.

Second, semantic priming appears to be somewhat affected by small amounts (up to three syllables) of intervening sentential material. While there is greater facilitation for primed items under the immediate than under the delay presentation condition, the $t$ tests show that this interaction was caused by changes in the absolute amount of priming, not by its absence under any one condition. The presence of the significant interaction, however, does suggest that intervening material has an effect upon the semantic facilitation process. Of course, the presence of intervening sentential material was confounded with the passage of time in this manipulation. Thus, it is not possible to determine whether the decrement is a function of simple decay or interference (or both). The fact that semantic facilitation does occur at the three-syllable (approximately 1-sec) delay interval is interesting in that this is somewhat longer than the effective interval reported in a number of recent isolated-word automatic priming studies. This suggests the "automaticity" may, in fact, be adjustable under varying task or situational constraints. As semantic priming may play a major contextual role during sentence comprehension, one can conceive of advantages to prolonging the effect under such circumstances. In support of the assumptions underlying this position, it should be noted that the effect obtained in the delay condition is unlikely to be qualitatively different from that found in the immediate presentation condition. That is, there appear to be no grounds for supposing that anything but an automatic priming effect obtains in any condition of this study. There was no way to anticipate when a visual item would appear, whether or not it would be a word, whether or not a word would relate to something in the sentence, and, even if it did, whether the item to which it related was distant or nearly coincident with the visual item. If subjects were to use a special strategy, such as one in which they might attempt to relate temporally adjacent materials, one would expect a significant increase in both the number of errors in the delay condition and the reaction times to control materials in this condition. Neither of these effects occurred. Interestingly, in posttest questioning sessions subjects did not report having noticed the relevant relationships between auditory and visual materials. Onset of the visual word apparently undergoes perceptual displacement (downstream from its objective placement), and subjects tend to notice only general relationships between some of the sentences and the visual words.

Finally, and perhaps of greatest interest, semantic priming is apparently unaffected by the presence of a clause boundary intervening between the priming and the primed items. At first glance this may seem a rather surprising result, given arguments as to the function of the clause in ongoing sentence perception. In the clause boundary condition of this experiment, subjects were presented with a clear cue (usually a single-syllable relative pronoun) indicating that the previous clause had been completed and that a new clause had begun. This is particularly true in the delay condition, where not only a relative pronoun but also another twosyllable word was typically completed before the visually presented word appeared. If there is substance to the argument that hypothesis-driven components of the comprehension device determine when completion of clausal units has occurred (in order to facilitate the establishment of appropriate structural descriptions; see, e.g., Fodor et al., 1974), then the clauses in these materials should have been marked as "completed" prior to occurrence of the visual item. Thus, it appears reasonable to assume that the effect is exactly what it seems to be-evidence that structural analysis (at least in the form of clausal closure) does not disrupt or interact with automatic semantic priming processes.

This conclusion forces at least some reconsideration of claims regarding the fate of a clause following its comple. tion. Certainly, the claim that clausal information is shifted from working memory following completion (Caplan, 1972) must be considered suspect, insofar as working memory is viewed as the place where information processing occurs. That is, as long as working memory is conceived of as the (only) place where active processing of information occurs, the current results are at odds with this claim. Some works from the fields of attention (e.g., Lackner \& Garrett, 1972) and cognitive bases of consciousness, however, provide a basis for reconciliation. In this work it has become clear that much information processing takes place even when attended work ing memory is otherwise occupied. Thus, even when certain information, such as that contained in completed clauses, is no longer available to immediate conscious 
access, some processing (such as that involved in semantic priming) may continue to take place. Tasks that depend on conscious access of this nonconscious information (such as Caplan's probe task) will not meet with easy success; but those tasks that reflect the end (conscious) results of this nonconscious information processing (such as the present task) will directly reflect the fact that such processing has taken place. On the other hand, information in clauses that are under current scrutiny is more available to conscious access and thus more amenable to study by tasks of all types. It appears that automatic semantic facilitation such as that investigated here takes place whether or not the relevant information is undergoing conscious scrutiny. Certainly, we know that general semantic information about lexical material that has been transferred to long-term memory exists, and thus could provide the basis for such priming (Jarvella, 1971). The apparent conflict in the data concerning clausal processing can thus be resolved by considering the conscious or nonconscious nature of information being examined by any particular experimental task. Note that it is an automatic process that is under study in this paper and that these results may not hold for processes of a more controlled and strategic nature (cf. Shiffrin \& Schneider, 1977). Finally, it is interesting to note that the effect obtained here across clause boundaries is similar in many ways to the contextual facilitation found also to hold across clause boundaries by Swinney and Hakes (1976).

In sum, the data from Experiments 1 and 2 suggest that automatic semantic priming obtains both crossmodally and during ongoing sentence comprehension, that it is independent from the establishment of a structural description for a sentence, and that the effect is subject to decay and/or interference during sentence comprehension. Although the extent of application of each of these conclusions has not yet been determined, the results open some interesting doors to the study of lexical processing during sentence comprehension.

\section{REFERENCE NOTES}

1. Meyer, D. E., Schvaneveldt, R. W., \& Ruddy, M. G. Activation of lexical memory. Paper presented at the meeting of the Psychonomic Society, St. Lou is, November 1972.

2. Schulman, H. G., \& Davidson, T. C. Coding of phonemic and semantic information in word pairs. Paper presented at the meeting of the Midwestern Psychological Association, May 1978.

3. Holley-Wilcox, P. The effect of homophony with auditory presentation of stimuli. Paper presented at the meeting of the Mid. western Psychological Association, Chicago, May 1977.

4. Cutler, A., \& Foss, D. G. Comprehension of ambiguous sentences: The locus of context effects. Paper presented at the meeting of the Midwestern Psychological Association, Chicago, May 1974.

\section{REFERENCES}

Blank, M. A., \& Foss, D. F. Semantic facilitation and lexical access during sentence processing. Memory \& Cognition, 1978 , 6. 644-652.
CAPLAN, D. Clause boundaries and recognition latencies for words in sentences. Perception \& Psychophysics, 1972, 12, 72-77.

CARPenter, P. A., \& Just, M. A. Sentence comprehension: A psycholinguistic processing model of verification. Psychological Review, 1975, 82, 45-73.

Clark, H. H. The language-as-fixed-effect fallacy: A critique of language statistics in psychological research. Journal of Verbal Learning and Verbal Behavior, 1973, 12, 335-359.

Cohene, L. S., Smith, M. C., \& Klein, D. Semantic satiation revisited with a lexical decision task. Memory \& Cognition, 1976, 6, 131-140.

Collins, A. M., \& Loftus, E. F. A spreading-activation theory of semantic processing. Psychological Review, 1975, 82, 407-428.

CUTLER, A., \& NorRIs, D. Monitoring sentence comprehension. In W. E. Cooper \& E. C. T. Walker (Eds.), Sentence processing: Psycholinguistic studies presented to Merrill Garrett. Erlbaum, in press.

FISHLER, I. Associative facilitation without expectancy in a lexical decision task. Journal of Experimental Psychology: Human Perception and Performance, 1977, 3, 18-26.

Fodor, J. A., Bever, T. G., \& Garrett, M. F. The psychology of language: An introduction to psycholinguistics and generative grammar. New York: McGraw-Hill, 1974.

Forback, G. B., Stanners, R. F., \& Hochhaus, L. Repetition and practice effects in a lexical decision task. Memory \& Cognition, 1974, 2, 337-349.

Foss, D. J., \& Jenkins, C. Some effects of context on the comprehension of ambiguous sentences. Journal of Verbal Learning and Verbal Behavior, 1973, 12, 577-589.

Gehring, R. E., Toglia, M. P., \& Kimble, G. A. Recognition memory for words and pictures at short and long retention intervals. Memory \& Cognition, 1976, 4, 256-260.

Harris, P., Morris, P., \& Bassett. E. Classifying pictures and words: Implications for the dual-coding hypothesis. Memory \& Cognition, 1977, 5, 242-246.

JARVELLA, R. Syntactic processing of converted speech. Journal of Verbal Learning and Verbal Behavior, 1971, 10, 409-416.

Jenkins, J. J. The 1952 Minnesota word association norms, In L. Postman \& G. Keppel (Eds.), Norms of word association. New York: Academic Press, 1970.

KuČERA, H., \& Francis, W. Computational analysis of presentday American English. Providence, R.I: Brown University, 1967.

LACKNER, J. R., \& GARRETT, M. F. Resolving ambiguity: Effects of biased concepts in the unattended ear. Cognition, 1972, 1, 359-372.

Marslen-Wilson, W. D., \& Welsh, A. Processing interactions and lexical access during word recognition in continuous speech. Cognitive Psychology, 1978, 10, 29-64.

MEYer, D. E., SchVaneveldt, R. W., \& RudDY, M. Loci of contextual effects on visual word recognition. In P. M. A. Rabbitt \& S. Dornic (Eds.), Attention and Performance V. New York: Academic Press, 1975.

MoRTon, J., \& Long, J. Effect of word transitional probability on phoneme identification. Journal of Verbal Learning and Verbal Behavior, 1976, 15, 43-51.

NeELy, J. Semantic priming and retrieval from lexical memory: Roles of inhibitionless spreading activation and limited-capacity attention. Journal of Experimental Psychology: General, 1977, 106, 226-254.

Pellegrino, J. W., Rosinski, R., Chiesi, H., \& Siegel, A. Picture-word differences in decision latency: An analysis of single and dual memory models. Memory \& Cognition, 1977, 5, 387.396.

Posner, M. I., \& Snyder, C. R. Attention and cognitive control. In R. Solso (Ed.), Information processing and cognition. Hillsdale, N.J: Erlbaum, 1975.

PostMAN, L., \& KEPPEL, G. (Eds.). Norms of word association. New York: Academic Press, 1970.

Rubenstein, H., Lewis, S. S., \& Rubenstein, M. A. Homo- 
graphic entries in the internal lexicon: Effects of systematicity and relative frequency of meanings. Journal of Verbal Learning and Verbal Behavior, 1971, 10, 57-62.

Shiffrin, R. M.. \& Schneider, W. Controlled and automatic human information processing: II. Perceptual learning, automatic attending, and a general theory. Psychological Review, $1977,84,127-190$

Swinney, D. A.. \& Hakes, D. T. Effects of prior context upon lexical access during sentence comprehension. Journal of Verbal
Learning and Verbal Behavior, 1976, 15, 681-689.

Tweedy, J., Lapinski, R. H., \& Schvaneveldt, R. W. Semantic context effects on word recognition: Influence of varying proportion of items presented in an appropriate context. Memory \& Cognition. 1977, 5. 84-89.

(Accepted for publication March 14, 1979.) 